\title{
Optimal Adaptive Controller Based on STATCOM and UPFC
}

\author{
Reza Hemmati*, Hamidreza Koofigar ${ }^{\dagger}$ and Mohammad Ataei**
}

\begin{abstract}
In this paper, an advanced and modified MRAS technique is utilized for controller design in electric power systems. The weighting factors of the proposed MRAS are tuned by using PSO. This optimal-adaptive controller is also normalized by normalization techniques to guarantee the system stability. The proposed MRAS then is applied to design STATCOM stabilizer and UPFC power flow controller. STATCOM stabilizer is a regulatory controller, while the power flow controller of UPFC is a tracking one. Therefore, the ability of the proposed MRAS technique to design regulatory and tracking controllers is investigated. In order to indicate the effectiveness of the proposed method, it is evaluated against the conventional methods. Simulation results demonstrate the validity of the method, under uncertainties and different disturbances.
\end{abstract}

Keywords: Model Reference Adaptive System, Static Synchronous Compensator, Supplementary Stabilizer, Unified Power Flow Controller

\section{Introduction}

Electric power components are mainly controlled through internal or external supplementary controllers. Synchronous generator, UPFC, STATCOM, and SVC are the wellknown components which apply internal or supplementary controllers [1]. In order to reach a suitable performance, many different control methods have been utilized in power systems [1-3]. This paper deals with controller design based on the MRAS technique to control power flow and damp out oscillations in power systems. Where, STATCOM stabilizer and UPFC power flow controller are designed based on the MRAS technique. STATCOM performances based on the principle that a voltage-source inverter generates a controllable AC voltage source behind a transformer-leakage reactance so that the voltage difference across the reactance produces active and reactive power exchange between the STATCOM and the network. STATCOM can be used to provide voltage support and stability improvement [4]. When STATCOM is used to damp out the oscillations and stability improvement, a supplementary stabilizer is equipped based on STATCOM. UPFC is also the most comprehensive and feasible FACTS devices. UPFC can successfully control power flow, voltage and also alter line impedance [4]. The main purpose of UPFC is to control of power flow in transmission lines which is a tracking characteristic.

As stated above, supplementary stabilizer of STATCOM is used to damp out the oscillations, but, UPFC is mainly utilized to track power flow in transmission lines. In this

$\dagger$ Corresponding Author: Department of Electrical Engineering, University of Isfahan, Isfahan, Iran. (koofigar@eng.ui.ac.ir)

* Department of Electrical Engineering, Kermanshah University of Technology, Kermanshah, Iran. (r.hemmati@kut.ac.ir)

** Department of Electrical Engineering, University of Isfahan, Isfahan, Iran. (ataei@eng.ui.ac.ir)

Received: October 30, 2015; Accepted: February 22, 2016 paper, MRAS method is used to design supplementary stabilizer of STATCOM and power flow controller of UPFC. MRAS is an effective adaptive method to deal with system uncertainties. The proposed MRAS controllers are evaluated against conventional controllers. To verify the proposed method under uncertainties, power system including uncertainties as well as different disturbances is simulated. Results show that the proposed adaptive controller can successfully control power system and damp out the oscillations under different conditions and faults.

\section{Model Reference Adaptive System}

The MRAS is a control method in which the desired performance is defined as a reference model. Then, the system with MRAS controller tracks the reference model following any command in input [5]. In fact, the idea behind MRAS is to create a closed loop controller with parameters that can be updated to change the response of the system to follow a desired model. MRAS method comprises two feedback loops, the ordinary feedback loop is used to compose the process and the controller and another feedback loop to adjust the controller parameters. The parameters adjustment is carried out based on the tracking error which is defined as the difference between the output of the system and the output of the reference model. The methodology of parameters adjustment in MRAS is obtained by different methods such as gradient method or Lyapunov stability theory [5]. In the proposed method, Lyapunov stability theory guarantees the stability of system under the proposed MRAS controller [5].

\subsection{MRAS design for a typical system}

In this section, the MRAS design for a typical plant is presented. It is assumed that the plant model is described by 


$$
y=\frac{k_{p}\left(s+b_{0}\right)}{s^{2}+a_{1} s+a_{0}} u
$$

where, $u$ is a control variable, $y$ is the measured output, $a_{0}$, $a_{1}, b_{0}>0$ are some real constants and $k_{p}$ represents the gain. Also, the reference model is considered as

$$
y_{m}=\frac{k_{m}}{s+a_{m}} u_{c}
$$

in which $k_{m}$ shows the gain and $a_{m}$ represents the pole of reference model. In this case, the MRAS controller is given by

$$
u_{p}(t)=\theta_{1}(t) w_{1}(t)+\theta_{2}(t) w_{2}(t)+\theta_{3}(t) y+\theta_{4}(t) u_{c}
$$

where,

$$
\begin{aligned}
& \frac{\mathrm{dw}_{1}}{\mathrm{dt}}=\mathrm{Fw}_{1}+\mathrm{gu} \\
& \frac{\mathrm{dw}_{1}}{\mathrm{dt}}=\mathrm{Fw}_{2}+\mathrm{gy} \\
& \mathrm{u}=\theta^{\mathrm{T}} \mathrm{w} \\
& \theta=\left[\begin{array}{llll}
\theta_{1}^{\mathrm{T}} & \theta_{2}{ }^{\mathrm{T}} & \theta_{3} & \theta_{4}
\end{array}\right] \\
& \mathrm{w}=\left[\begin{array}{llll}
\mathrm{w}_{1}^{\mathrm{T}} & \mathrm{w}_{2}{ }^{\mathrm{T}} & \mathrm{y} & \mathrm{u}_{\mathrm{c}}
\end{array}\right]
\end{aligned}
$$

In the above equations, the $F$ and $g$ are chosen by designer. By using the Lyapunov stability theorem the adaption rule for $\theta$ is obtained as (4) and $\Gamma$ is chosen as (5) and adaption rule for $\theta_{i}$ is given by (6).

$$
\begin{aligned}
& \frac{\mathrm{d} \theta}{\mathrm{dt}}=-\Gamma \text { ew } \\
& \Gamma=\operatorname{diag}\left(\gamma_{\mathrm{i}}\right) \\
& \frac{\mathrm{d} \theta_{\mathrm{i}}}{\mathrm{dt}}=-\gamma_{\mathrm{i}} \mathrm{ew}_{\mathrm{i}}
\end{aligned}
$$

where, $e$ is the difference between the output of the system and the output of the reference model. Also, the parameter $\gamma$ is weighing factor, chosen by the designer.

\section{Tracking and Regulatory Controllers}

This paper designs STATCOM stabilizer as a supplementary regulatory controller to add stabilizing signal to STATCOM. The conventional stabilizer is commonly considered as a lead-lag compensator. The output signal of the stabilizer is used as an additional input to STATCOM. The stabilizer input signal can be either the machine speed deviation $(\Delta \omega)$ or its acceleration power. In this paper, the output signal of the stabilizer is pulse width modulation (PWM) index of STATCOM $\left(\mathrm{m}_{\mathrm{E}}\right)$ and the stabilizer input signal is the machine speed deviation $(\Delta \omega)$. As well, this paper investigates the ability of UPFC in power flow control. UPFC power flow controller is a tracking type controller that controls the power flow of the line on which UPFC is installed. Power flow controller of UPFC is usually a PI type controller. But, this simple PI controller cannot appropriately operate under different operating conditions. Therefore, an adaptive power flow controller based on MRAS method is designed for UPFC.

\section{Illustrative Test Cases}

In this paper two test systems are considered to design the proposed controllers. IEEE 14 bus test system is used as the first test case, in which, STATCOM is installed on bus 14 . This system is considered to evaluate the proposed MRAS stabilizer based on STATCOM. The system data for IEEE 14 bus test system are given in [6]. A single-machine infinite bus system installed with UPFC is also considered as the second test case. The system data for the second test case are presented in [7]. The second test case is considered to evaluate the proposed MRAS tracking controller based on UPFC. Furthermore, three different loading as nominal, light, and heavy are considered and listed in Table 1.

Table 1. Loading conditions for all test cases

\begin{tabular}{c|c|c|c}
\hline Loading condition & light & nominal & heavy \\
\hline \multirow{2}{*}{ value } & $\mathrm{P}_{\text {nominal }} \times 80 \%$ & $\mathrm{P}_{\text {nominal }}$ & $\mathrm{P}_{\text {nominal }} \times 120 \%$ \\
& $\mathrm{Q}_{\text {nominal }} \times 90 \%$ & $\mathrm{Q}_{\text {nominal }}$ & $\mathrm{Q}_{\text {nominal }} \times 110 \%$ \\
\hline
\end{tabular}

\section{Dynamic Model of Power System}

The generators are modeled here as two-axis, three-order model. For all operating conditions, the power system with generators, excitation systems and turbine-governor systems can be modeled by a set of nonlinear differential equations as (7) [8].

$$
\dot{\mathrm{x}}=\mathrm{f}(\mathrm{x}, \mathrm{u})
$$

where $\mathrm{x}=\left(\delta, \omega, \mathrm{E}_{\mathrm{q}}^{\prime}\right)$ and $\mathrm{u}$ are the vector of state variables. The nonlinear dynamic model of the system can be rewritten as (8) [8]. As well, a linear dynamic model can be derived as (9). Where, $\mathrm{A}$ is the power system state matrix, $\mathrm{B}$ is the input matrix, $\mathrm{C}$ is the output matrix, $\mathrm{D}$ is the feedforward matrix.

$$
\left\{\begin{array}{l}
\dot{\omega}_{\mathrm{i}}=\frac{\left(\mathrm{P}_{\mathrm{m}}-\mathrm{P}_{\mathrm{e}}-\mathrm{D} \omega\right)}{\mathrm{M}} \\
\dot{\delta}_{\mathrm{i}}=\omega_{0}(\omega-1) \\
\mathrm{E}_{\mathrm{qi}}^{\prime}=\frac{\left(-\mathrm{E}_{\mathrm{q}}+\mathrm{E}_{\mathrm{fd}}\right)}{\mathrm{T}_{\mathrm{do}}^{\prime}} \\
\dot{\mathrm{E}_{\mathrm{fdi}}}=\frac{-\mathrm{E}_{\mathrm{fd}}+\mathrm{K}_{\mathrm{a}}\left(\mathrm{V}_{\mathrm{ref}}-\mathrm{V}_{\mathrm{t}}\right)}{\mathrm{T}_{\mathrm{a}}}
\end{array}\right.
$$




$$
\left\{\begin{array}{l}
\dot{x}=A x+B u \\
y=C x+D u
\end{array}\right.
$$

\subsection{Dynamic model including STATCOM and UPFC}

Power system modeling including STATCOM and UPFC is completely reported in [9] and [10]. The nonlinear dynamic models of the system including STATCOM and UPFC are given as (10) and (11), respectively. Where, the first four equations indicate the generators dynamic model and the last equation represents the FACTS device dynamic model.

$$
\begin{aligned}
& \left\{\begin{array}{l}
\dot{\omega}_{\mathrm{i}}=\frac{\left(\mathrm{P}_{\mathrm{m}}-\mathrm{P}_{\mathrm{e}}-\mathrm{D} \omega\right)}{\mathrm{M}} \\
\dot{\delta_{\mathrm{i}}}=\omega_{0}(\omega-1) \\
\mathrm{E}_{\mathrm{qi}}^{\prime}=\frac{\left(-\mathrm{E}_{\mathrm{q}}+\mathrm{E}_{\mathrm{fd}}\right)}{\mathrm{T}_{\mathrm{do}}^{\prime}} \\
\dot{\mathrm{E}_{\mathrm{fdi}}}=\frac{-\mathrm{E}_{\mathrm{fd}}+\mathrm{K}_{\mathrm{a}}\left(\mathrm{V}_{\mathrm{ref}}-\mathrm{V}_{\mathrm{t}}\right)}{\mathrm{T}_{\mathrm{a}}} \\
\dot{\mathrm{V}_{\mathrm{dc}}}=\frac{3 \mathrm{~m}_{\mathrm{E}}}{4 \mathrm{C}_{\mathrm{dc}}}\left(\sin \left(\delta_{\mathrm{E}}\right) \mathrm{I}_{\mathrm{Ed}}+\cos \left(\delta_{\mathrm{E}}\right) \mathrm{I}_{\mathrm{Eq}}\right)
\end{array}\right. \\
& \left\{\begin{array}{l}
\dot{\omega}=\frac{\left(P_{m}-P_{e}-D \Delta \omega\right)}{M} \\
\dot{\delta}=\omega_{0}(\omega-1) \\
\dot{E}_{q}^{\prime}=\frac{\left(-E_{q}+E_{f d}\right)}{T_{d o}^{\prime}} \\
\dot{E}_{f d}=\frac{-E_{f d}+K_{a}\left(V_{r e f}-V_{t}\right)}{T_{a}} \\
\dot{V}_{d c}=\frac{3 m_{E}}{4 C_{d c}}\left(\sin \left(\delta_{E}\right) I_{E d}+\cos \left(\delta_{E}\right) I_{E q}\right)+ \\
\frac{3 m_{B}}{4 C_{d c}}\left(\sin \left(\delta_{B}\right) I_{B d}+\cos \left(\delta_{B}\right) I_{B q}\right)
\end{array}\right.
\end{aligned}
$$

\section{Controller Design Using MRAS}

\subsection{Stabilizer design based on STATCOM for test case 1}

Stabilizer design based on STATCOM is a regulatory controller design. In this case, MRAS stabilizer is designed based on the proposed model and the reference model is considered as (12) :

$$
\mathrm{y}=\frac{1 \times 10^{-3} \mathrm{~s}(\mathrm{~s}+1)}{\mathrm{s}^{2}+2 \mathrm{~s}+2} \mathrm{u}
$$

In order to show the effectiveness of the proposed
Table 2. Parameters of the conventional stabilizer

\begin{tabular}{c|c|c|c|c|c}
\hline Parameter & $\mathrm{K}$ & $\mathrm{T}_{1 \mathrm{n}}$ & $\mathrm{T}_{1 \mathrm{~d}}$ & $\mathrm{~T}_{2 \mathrm{n}}$ & $\mathrm{T}_{2 \mathrm{~d}}$ \\
\hline value & 0.46 & 0.01 & 0.01 & 1.00 & 0.16 \\
\hline
\end{tabular}

MRAS stabilizer, the conventional stabilizer is also designed. The parameters of the conventional stabilizer are obtained using PSO algorithm. STATCOM stabilizer design by using PSO is completely presented in [11]. In order to stabilizer design using PSO, the objective function is considered as (13). The optimum values of the parameters are obtained using PSO and summarized in the Table 2. It is worth mentioning that paper [11] designs STATCOM stabilizer by PSO technique. But, in the current paper, STATCOM stabilizer is designed by MRAS technique. Then MRAS-stabilizer and PSO-stabilizer are compared to demonstrate the superiority and new contribution of current paper over [11].

$$
\operatorname{ITAE}=\sum_{i=1}^{n} \int_{0}^{\mathrm{t}} \mathrm{t}\left|\Delta \omega_{\mathrm{i}}\right| \mathrm{dt}
$$

\subsection{UPFC power flow controller design for test case 2}

UPFC power flow controller is a tracking controller which controls power flow in line. In order to design the tracking controller, a reference model is adopted to reflect the desired specifications. Acceptable properties such as speed of time response (rise time), overshoot and settling time may be obtained by choosing the reference model as (14).

$$
y=\frac{11.5}{s^{2}+6 s+11.5} u
$$

In order to provide a comparative study, a PI controller is also designed for UPFC. The parameters of the proposed PI controller are adjusted using PSO. UPFC controllers design using PSO is given by [12]. The objective function is considered as (14). The parameters of the proposed PI controller are listed in Table 3.

Table 3. Parameters of PI power flow controller

\begin{tabular}{c|c|c}
\hline & Proportional gain & Integrator gain \\
\hline value & 0.207 & 4.777 \\
\hline
\end{tabular}

\section{Results and Discussions}

\subsection{Simulation results of test case 1}

The designed MRAS and conventional stabilizers are simulated on test system 1 . The system disturbances are defined as follows:

Disturbance 1: 6-cycle three phase short circuit in bus 12

Disturbance 2: 10-cycle three phase short circuit in bus 6 
Table 4. ITAE for test case 1

\begin{tabular}{c|c|c|c|c}
\hline \multirow{2}{*}{$\begin{array}{c}\text { Operating } \\
\text { condition }\end{array}$} & \multicolumn{2}{|c|}{ Disturbance 1 } & \multicolumn{2}{c}{ Disturbance 2 } \\
\cline { 2 - 5 } & MRAS & Conventional & MRAS & Conventional \\
\hline Nominal & 0.029 & 0.031 & 0.106 & 0.168 \\
Heavy & 0.131 & 0.142 & 0.119 & 0.176 \\
Light & 0.018 & 0.029 & 0.070 & 0.140 \\
\hline
\end{tabular}

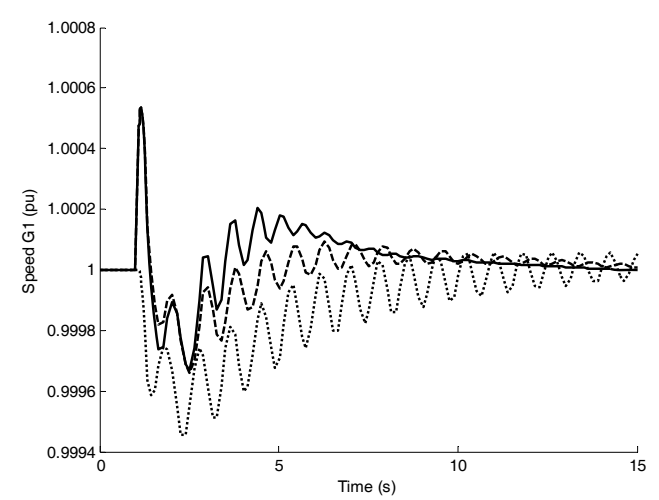

Fig. 1. Generator speed at nominal condition following disturbance 1. Solid: MRAS stabilizer; Dashed: conventional stabilizer; Dotted: without stabilizer

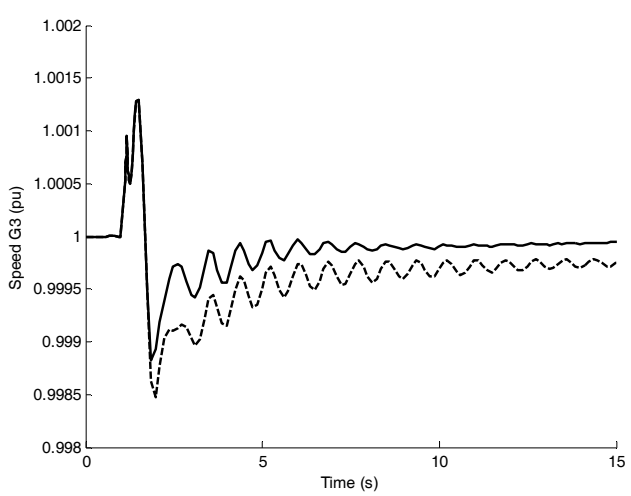

Fig. 2. Generator speed at heavy condition under disturbance 2. Solid: MRAS; Dashed: Conventional

The ITAE index is calculated for both the MRAS and conventional stabilizers. The ITAE index is a suitable index to study and compare the proposed methods. The ITAE is calculated in all operating conditions under different disturbances and results are listed in Table 4. MRAS stabilizer shows better performance than the conventional stabilizer at all operating conditions.

Figs. 1-2 show the simulation results under different conditions. The response in the nominal operating condition and following disturbance 1 is depicted in Fig. 1. In order to show the impacts of the stabilizers, the responses without stabilizers are also presented in some cases. It is clear that the MRAS stabilizer shows a significant advantage over the conventional stabilizer. The proposed MRAS stabilizer successfully damp out the oscillations as fast as possible. As well, the responses without stabilizer demonstrate that the system without stabilizer does not provide enough damping, and the oscillations cannot be damp out rapidly.
The simulation result under heavy loading condition following disturbance 2 is also depicted in Fig. 2. The figure shows that the proposed MRAS has still a good performance. But, the conventional stabilizer does not show an appropriate performance under this condition.

Since MRAS stabilizer is based on the adaptive rules, this stabilizer presents a suitable performance under different loading conditions. It can be concluded that the MRAS method has suitable parameter adaptation compared to the conventional method while operating condition changes. Eventually, the result without stabilizer emphasize on the importance of the stabilizer, and system without stabilizer goes to oscillations following disturbance.

\subsection{Simulation results of test case 2}

In this case, simulations are carried out on the test system 2. The ITAE is calculated following $10 \%$ step change in the reference mechanical torque $\left(\Delta T_{m}\right)$ at all operating conditions and results are listed in Table 5. It is clear that MRAS has better performance than PI at all operating conditions. With changing operating condition from nominal to heavy, the priority of MRAS becomes clearer.

Also simulation results following 0.1 step change in the reference power of transmission line (line which is equipped by UPFC) in the nominal operating condition are shown in Fig. 3. When the reference power of UPFC is increased by 0.1 , the power in line (the line on which UPFC is installed) is increased to 0.1 . Therefore, UPFC can successfully alter power flow in the line based on the command reference. The deviation of synchronous speed is also illustrated in Fig. 4. In all cases, MRAS method has better performance than classic method.

Table 5. ITAE for test case 2

\begin{tabular}{c|c|c}
\hline Operating condition & Optimized-PI & MRAS-PSO \\
\hline Nominal & 0.073 & 0.069 \\
\hline Heavy & 0.389 & 0.098 \\
\hline Light & 0.073 & 0.070 \\
\hline
\end{tabular}

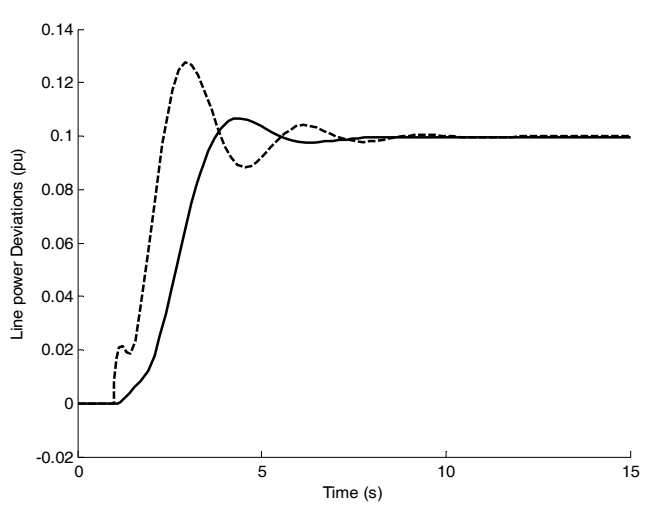

Fig. 3. Line power following $10 \%$ step change in $\mathrm{P}_{\text {ref }}$ of line at nominal condition. Solid: MRAS; Dashed: Optimized PI 
Table 6. Weighting factors of UPFC controller

\begin{tabular}{c|c|c|c|c}
\hline & $\gamma_{1}$ & $\gamma_{2}$ & $\gamma_{3}$ & $\gamma_{4}$ \\
\hline PSO & 19.21 & 14.60 & 10.53 & 254.77 \\
\hline Try and error & 23.11 & 12.08 & 10.10 & 241.90 \\
\hline
\end{tabular}

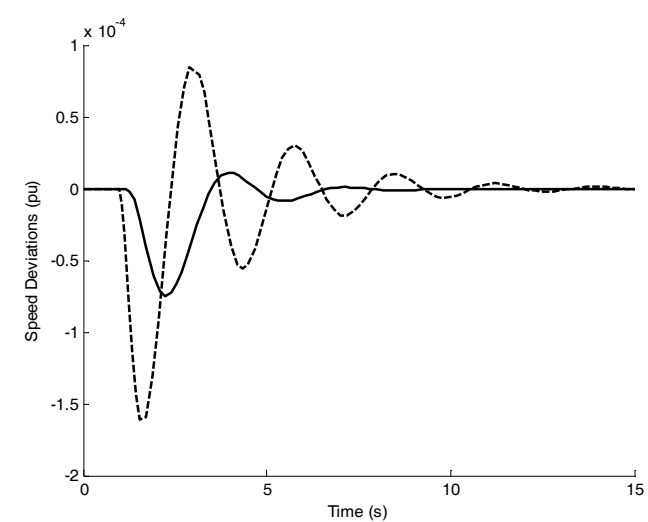

Fig. 4. Speed deviations following 10\% step change in $\mathrm{P}_{\text {ref }}$ of line under heavy condition. Solid line: MRAS; Dashed line: Optimized PI

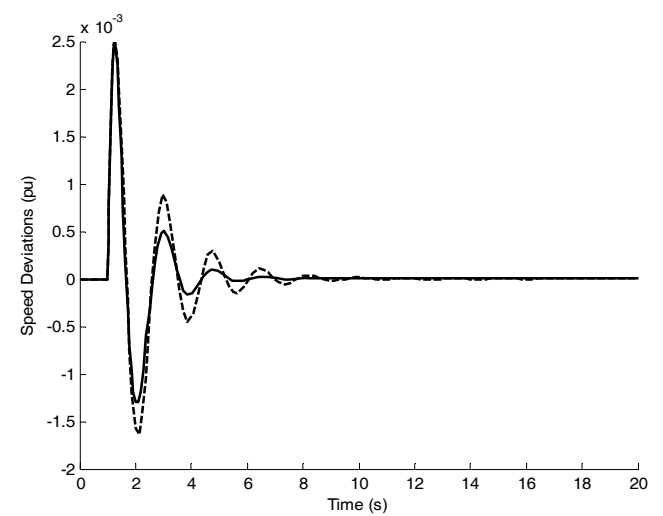

Fig. 5. Speed deviations following $15 \%$ step change in $P_{m}$. Solid: PSO; Dashed: Try and error

\subsection{Sensitivity analysis on the weighting factors}

As stated, weighting factors of MRAS are tuned using PSO. The advantage or good performance of a use of PSO over 'try-error' is investigated. Table 6 indicates the weighting factors of UPFC controller in test case 2 by different tuning methods. Fig. 5 shows $\Delta \omega$ following $15 \%$ step change in the $\Delta \mathrm{P}_{\mathrm{m}}$ under PSO and 'try-error' methods. It is clear that PSO presents better performance. PSO mainly finds the optimal weighting factors and leads to a global solution; while 'trial and error' usually resulted in a local solution and does not obtain the best response.

\section{Conclusions}

This paper applies MRAS to design tracking and regulatory controllers, based on the UPFC and STATCOM, respectively. In order to indicate the performance of MRAS under uncertainties, different loading conditions and disturbances are simulated. As well, the proposed MRAS controllers are evaluated against the conventional algorithms. Simulation results demonstrate robustness of the proposed adaptive method under different operating conditions and disturbances. Results show that MRAS can assure robust stability and robust performance under wide-ranging uncertainties and disturbances.

\section{Nomenclature}

\section{Symbols}

$\mathrm{m}_{\mathrm{B}}$ : PWM index of series converter

$\mathrm{m}_{\mathrm{E}}$ : PWM index of shunt converter

$\delta_{\mathrm{B}}$ : Phase angle of series injected voltage

$\delta_{\mathrm{E}} \quad$ : Phase angle of shunt injected voltage

M : System inertia (Mj/MVA)

$\Delta \quad$ : Rotor angle

$\Omega \quad$ : Rotor speed (pu)

$\mathrm{P}_{\mathrm{m}}$ : Mechanical input power (pu)

$\mathrm{T}_{\mathrm{m}}$ : Mechanical torque (pu)

$\mathrm{P}_{\mathrm{e}} \quad$ : Electrical output power $(\mathrm{pu})$

$\mathrm{E}_{\mathrm{q}}^{\prime}$ : Internal voltage behind $\mathrm{x}_{\mathrm{d}}^{\prime}(\mathrm{pu})$

$\mathrm{E}_{\mathrm{fd}}$ : Equivalent excitation voltage $(\mathrm{pu})$

$\mathrm{X}_{\mathrm{d}}^{\prime}$ : Transient reactance of $\mathrm{d}$ axis $(\mathrm{pu})$

$\mathrm{X}_{\mathrm{q}}$ : Steady state reactance of $\mathrm{q}$ axis (pu)

$\mathrm{X}_{\mathrm{d}}$ : Steady state reactance of $\mathrm{d}$ axis $(\mathrm{pu})$

$\mathrm{Te}:$ Eectric torque (pu)

$\mathrm{T}_{\mathrm{do}}^{\prime}$ : Time constant of excitation circuit (s)

$\mathrm{K}_{\mathrm{a}}$ : Regulator gain

$\mathrm{T}_{\mathrm{a}} \quad$ : Regulator time constant (s)

$\mathrm{I}_{\mathrm{Eq}}$ : Current of $\mathrm{q}$ axis of shunt transformer (pu)

$\mathrm{I}_{\mathrm{Bd}}$ : Current of $\mathrm{d}$ axis of series transformer $(\mathrm{pu})$

$\mathrm{I}_{\mathrm{Bq}}$ : Current of $\mathrm{q}$ axis of series transformer $(\mathrm{pu})$

$\mathrm{V}_{\mathrm{E}}$ : Output voltage of shunt converter $(\mathrm{pu})$

$\mathrm{V}_{\mathrm{B}}$ : Output voltage of series converter $(\mathrm{pu})$

$\mathrm{I}_{\mathrm{E}} \quad$ : Output current of shunt converter (pu)

$\mathrm{I}_{\mathrm{B}} \quad$ : Output current of series converter $(\mathrm{pu})$

$\mathrm{V}_{\mathrm{t}}$ : Terminal voltage $(\mathrm{pu})$

$\mathrm{C}_{\mathrm{DC}}$ : DC-link capacitor of $\operatorname{UPFC}(\mathrm{pu})$

$\mathrm{V}_{\mathrm{DC}}$ : DC voltage of UPFC (pu)

$\mathrm{I}_{\mathrm{Ed}}: \mathrm{d}$ axis current of shunt transformer $(\mathrm{pu})$

$\mathrm{X}_{\mathrm{T}}$ : Reactance of transmission line (pu)

\section{Abbreviations}

FACTS : Flexible AC Transmission System

ITAE : Integral of the Time multiplied Absolute value of the Error

MRAS : : Model Reference Adaptive System

PSO : Particle Swarm Optimization

STATCOM : Static Synchronous Compensator

SVC : Static Var Compensator 


\section{References}

[1] S. A. Taher, R. Hemmati, A. Abdolalipour and S. Akbari, "Comparison of different robust control methods in design of decentralized UPFC controllers," International Journal of Electrical Power \& Energy Systems, vol. 43, no. 1, pp. 173-84, 2012.

[2] R. Hemmati, M. Nikzad and S. Shams, S. Farahani, "Investigation of UPFC performance under system uncertainties," International Journal of Electrical Power \& Energy Systems, vol. 43, no. 1, pp. 1137-43, 2012.

[3] A. Khodabakhshian and R. Hemmati, "Multimachine power system stabilizer design by using cultural algorithms," International Journal of Electrical Power \& Energy Systems, vol. 44, no. 1, pp. 571-80, 2013.

[4] N. G. Hingorani, L. Gyugyi and M. El-Hawary. Understanding FACTS: concepts and technology of flexible AC transmission systems: IEEE press New York, 2000.

[5] K. J. Åström and B. Wittenmark. Adaptive control: Dover Publications, 2008.

[6] F. Milano. PSAT, MATLAB-based power system analysis toolbox. 2002.

[7] S. A. Taher, S. Akbari, A. Abdolalipour and R. Hematti, "Robust decentralized controller design for UPFC using -synthesis," Communications in Nonlinear Science and Numerical Simulation, vol. 15, no. 8, pp. 2149-61, 2010.

[8] P. Kundur, N. J. Balu and M. G. Lauby., Power system stability and control: McGraw-hill New York, 1994.

[9] HF Wang, "Phillips-Heffron model of power systems installed with STATCOM and applications," IEE Proceedings-Generation, Transmission and Distribution, vol. 146, no. 5, pp. 521-527, 1999.

[10] HF Wang, "Applications of modelling UPFC into multi-machine power systems," IEE ProceedingsGeneration, Transmission and Distribution, vol. 146, no. 3, pp. 306-312, 1999

[11] S. Panda and N. P. Padhy, "Optimal location and controller design of STATCOM for power system stability improvement using PSO," Journal of the Franklin Institute, vol. 345, no. 2, pp. 166-81, 2008.

[12] S M Shirvani Boroujeni, R. Hemmati, H. Delafkar and A. Safarnezhad Jalilzadeh Boroujeni, "Simultaneous Power Flow Control and Voltage Support Using UPFC," International Review of Electrical Engin-eering, vol. 6, no. 2, pp. 818-23, 2011.

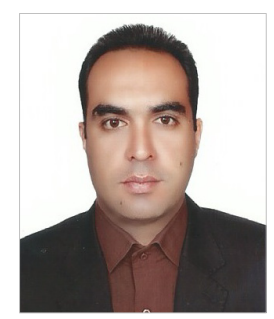

Reza Hemmati He received Ph.D. degree in electrical engineering from Isfahan University, Iran, 2013. Presently, he is assistant professor in Department of Electrical Engineering, Kermanshah University of Technology, Kermanshah, Iran. His research interests include power systems planning, operation and control.

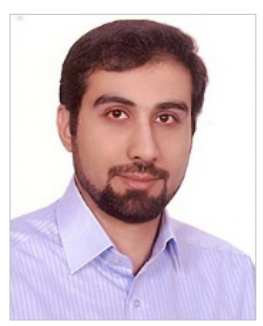

Hamidreza Koofigar He received the M.S. degree in Control Engineering in 2005 and his Ph.D. in Electrical Engineering in 2009, both from Isfahan University of Technology, Iran. He joined the Department of Electrical Engineering, University of Isfahan in 2010 , as an assistant professor. His current research interests include robust control, adaptive nonlinear control, and switched systems.

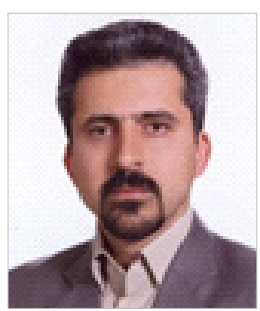

Mohamad Ataei He received the B.Sc. degree from the Isfahan University of Technology, Iran, in 1994, the M.Sc. degree from the Iran University of Science \& Technology, Iran, in 1997, and $\mathrm{PhD}$ degree from K. N. University of Technology, Iran, in 2004 (joint project with the University of Bremen, Germany) all in control Engineering. He is associate professor at the Department of Electrical Eng. at University of Isfahan, Iran. His main areas of research interest are control theory and applications, nonlinear control, and chaotic systems' analysis and control. 